\title{
An Interactive Steel Connection Teaching Tool - A Virtual Structure
}

\section{Prof. Saeed Moaveni, Minnesota State University, Mankato}

SAEED MOAVENI is Professor of Mechanical Engineering at Minnesota State University, Mankato. Dr. Moaveni has over 25 years of teaching and professional practice experience and is a registered P.E. in New York.

\section{Dr. Karen C. Chou, Northwestern University}

Karen C. Chou, Ph.D., P.E. is Assistant Chair and Clinical Professor at Northwestern University. Dr. Chou has over 30 years of teaching and professional experience and is a registered P.E. in 7 states. She was a recipient of Charles W. Britzius Distinguished Engineer Award from the Minnesota Federation of Engineering, Science and Technology Societies and the Civil Engineer of the Year from the Illinois Section ASCE. 


\title{
An Interactive Steel Connection Teaching Tool - A Virtual Structure
}

\begin{abstract}
Steel connections play important roles in the integrity of a structure, and many structural failures are attributed to connection failures. Connections are the glue that holds a structure together. The failures of the Hartford Civic Center in 1977, the Hyatt Regency Hotel in Kansas City in 1980, and the I-35W Bridge in Minneapolis in 2007 are all attributed to connection failures. A good connection design requires engineer to have a good understanding of the mechanics and steel behavior. The engineer also should know the fabricator's limitations and experience. In the past 20 years, in order to help students better understand various connection types; many schools have acquired steel sculptures. A steel sculpture is a physical system that shows forty-eight types of connections found in standard construction practices. Unfortunately, because of its size and location (eight feet tall, weighs nearly 2500 pounds and usually erected outdoor), students do not always have easy access to it. Moreover, today's students who belong to the Google generation are more comfortable with web-based learning tools. Through a NSF grant we have created an interactive version of the steel sculpture to provide not only an effective learning opportunity but also a 24-7 access to students and educators in the United States and abroad.
\end{abstract}

This work is the result of a collaborative effort among universities and students from different engineering programs. The virtual sculpture gives the user the freedom to rotate or pan the sculpture to view it from any direction. The user may also isolate any one of the 48 connections for a closer view and learn more about that given connection including: description of the connection, potential failure modes (limit states), sample calculations of each limit state to determine the load carrying capacity of the connection, field examples, and a 3-D finite element model of that connection. The 3-D model provides a visual display of stress distribution in the connection area.

The solid model of the steel sculpture was developed using Creo and converted to a 3-D interactive PDF file. This was done to avoid the need for purchasing the Creo software. A web page was also developed where users can download the virtual sculpture and the linked documents. Three survey forms were also developed with a slightly different focus to seek feedback from students, educators, and recent engineering graduates. The user may complete the online survey form after s/he has had an opportunity to explore the virtual sculpture. The capabilities of the virtual steel sculpture will be demonstrated during the presentation.

\section{Introduction}

A typical steel design course includes the following topics: determination of load combinations with appropriate load factors; sizing of tension (axial), compression (columns), and flexural (beam and girder) members; and design of tension connections using mechanical fasteners and welds. In some cases, time permitting, an instructor also may be able to cover additional topics such as shear-moment connection design. Furthermore, in a 15 week long semester, it is customary to teach "connections" during the last two weeks of the term. 
This lack of emphasis (accounting for approximately $10 \%$ of the course) is not a reflection of the significance of connections in design, instead, it is due to time constraints and the commonly mis-held belief that connections are standardized details that could and should be left to fabricators and detailers. However, connections, are the glue that holds a structure together, and as such deserve special emphasis to ensure sound structural integrity. Historically, connection failures have contributed to many structural failures. Examples include: the Hartford Civic Center in $1977^{[1]}$, the Hyatt Regency Hotel in Kansas City in $1980^{[2]}$, and, more recently, the I$35 \mathrm{~W}$ Bridge in Minneapolis ${ }^{[3]}$. Since the Hyatt Regency failure, many state licensing boards have made connection design the responsibility of the engineer-of-record. Moreover, there are situations for which standard connection types would not be applicable and engineers are required to design connections unique to those specific structures. A good connection design requires that the engineer have a good understanding of mechanics and steel behavior and an understanding of fabrication limitations. Often, what, theoretically, may appear to be an acceptable design, in practice, may become infeasible to fabricate in the shop or in the field. AISC Code of Standard Practice ${ }^{[4]}$ recommends that engineers work closely with the fabricators and detailers while designing connections. For these reasons, it is critically important that students, preparing to become practicing structural engineers, develop a good understanding of connection design, limitations, and assembly. Moreover, because of their three-dimensional nature, students have difficulty visualizing the assembly of connections of major components such as beams and columns.

The decision to create an interactive multi-media tool was made based on extensive research of the targeted audience and emerging engineers. Most faculty members who teach steel design belong to the baby boom generation. As such, they were taught using blackboards and black and white textbooks with limited illustrations. Engineers, in particular, were taught to understand and interpret orthographic views such as top, front, and side views. Today's students, as part of the "Google generation" are accustomed to whiteboards, multimedia presentations, multi-color textbooks with ample illustrations, and three-dimensional graphics. Most unique to the Google generation is the fact that they have grown up with the internet, a comprehensive toll that provides a number of resources including detailed graphics, downloading capabilities for music and movies, blogging, and tweeting. Cell phones, texting, and other electronic gadgets are also in wider use than any other time in history ${ }^{[5]}$. These societal factors are quantified in numerous surveys of college aged students in the U.S. ${ }^{[6-11]}$ which show that:

- $86 \%$ own a computer

- $97 \%$ have downloaded music and other media using peer-to-peer file sharing

- $93 \%$ own a cell phone

- $76 \%$ use instant messaging and social networking sites

- $76 \%$ of college students have a Facebook profile which they use over one hour a day

- $84 \%$ own some type of portable music and/or video device such as an iPod

- $63 \%$ of college students have internet capable handheld devices

- $49 \%$ regularly download music and other media using peer-to-peer file sharing

- $34 \%$ use websites as their primary source of news

- $28 \%$ author a blog and $44 \%$ read blogs

- $15 \%$ of IM (instant messaging) users are logged on 24 hours a day/7 days a week 
- Over one-quarter of students listed their laptop as the most important item in their bag which is almost three times the number of students who chose textbooks.

During the past two decades, there also have been many changes in the way lectures are delivered to students ${ }^{[13,14]}$. We have seen an increase in the use of physical models to help students better understand key concepts, and have moved from black boards to white boards and then to online deliveries (e.g., Blackboard, UCompass, Desire2Learn). We have transformed our classrooms to take advantage of new technologies. These efforts were all made in an attempt to narrow the generation gap, so that we can better connect with students and their learning styles.

Also, this period has seen a great deal of research dealing with the way in which people learn ${ }^{[15-}$ ${ }^{25]}$. One of the key characteristics on learning as discussed by Branford et al. ${ }^{[23]}$ is that initial learning is necessary for transfer; the application of previous knowledge in acquiring new knowledge. Although it may seem obvious, these studies show, conclusively, the benefits in the thorough understanding of transfer ${ }^{[15,23]}$. Additionally, the level of motivation a student has affects the amount of time a person is willing to spend on a subject in order to learn it. Learners are more motivated when they can see the usefulness of what they are learning ${ }^{[23]}$. Our understanding about the way people learn, in conjunction with the generational background provided the rationale for the development of an interactive multi-media tool for steel connection design.

Steel sculpture - the physical model

Steel connections have primarily designed as 2-dimensional elements ( $\mathrm{x}-\mathrm{y}$ and $\mathrm{y}-\mathrm{z}$ planes) despite the fact that their load bearing behavior is 3-dimensional. Combining two 2-D designs to yield a connection that supports a 3-D load bearing behavior is a concept that is usually very difficult for students to visualize. Figure 1 shows various views of the shear connection between a girder and two beams (Beams B3A and B3B which are connected to Girder B3). It is common to use two angle sections to connect them. One of the angles will be in the front face of beam $3 \mathrm{~A}$ and the other angle will be placed at the back face of beam 3A. The bolts will then connect all three elements together as shown in Figure 1b.

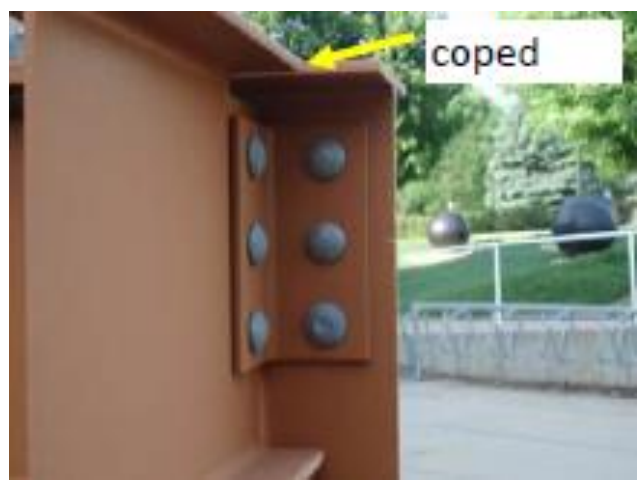

Figure 1a - Double bolted-angle shear connection, view 1

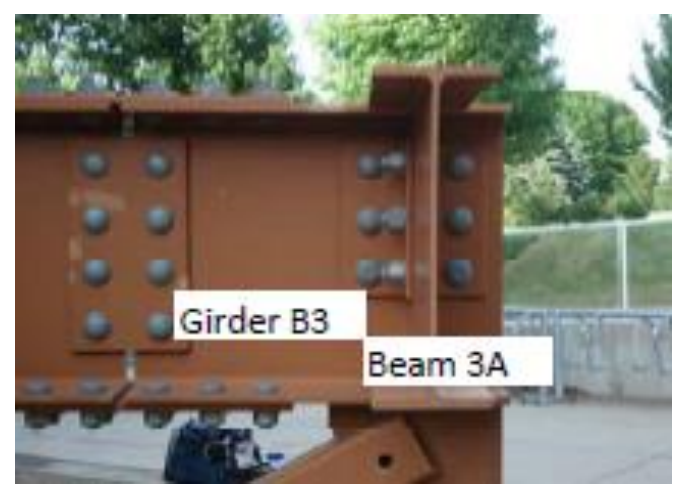

Figure $1 \mathrm{~b}$ - Double bolted-angle shear connection, view 2 


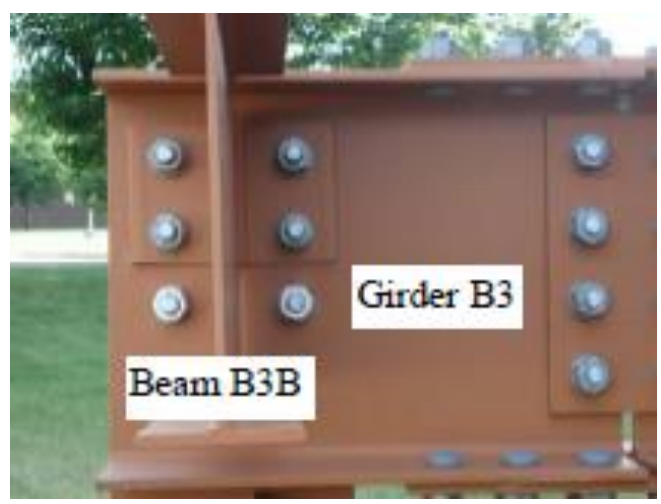

Figure 1c - Double bolted-angle shear connection, back of view 2

If only the view shown in Figure 1a were presented, it would be reasonable to conclude that the connection is a single-angle bolt connection. Figure $1 \mathrm{~b}$ allows us to see that this connection is obviously a double-angle connection. Further examination of the connection reveals that it is actually a two-double angle bolt and bolt-weld connection. The view in Figure 1c shows the back side of the view in Figure 1b. Obviously, it would be cumbersome to show all of the details for this connection on a blackboard or whiteboard. It would be even more difficult for the majority of students to visualize them.

Despite the increase usage of 3-D drafting, majority of the construction document and shop drawings are still produced in 2-dimensions. Figure 2 is an example of a typical shop drawing that would be provided by a fabricator to an engineer for review and approval. Although the shop drawing depicts exactly how the connection is to be assembled, it is not easily understood by the students. The main reason for this is that students typically have a one-semester course that exposes them to computer-aided-drafing in their freshman year, at a time when the students have little engineering background. This course is often taught by an instructor who has little to no experience in structural detailing. As for the above example, if students could not visualize the existence of another set of angles at the back face of Gider B3 (view shown in Figure 1b), it could lead to two common problems. First, students would not realize the signifcance and necessity of an additional set of angles. Second, due to the visual absence of the angles, the students would forget to include it in the design calculations, and this could affect the safety and integrity of a structure. Furthermore, the sculpture shows that the flange of Beams B3A and B3B must be coped to meet the top-of-steel-elevation requirement, often specified in design. This specific refers to the necessity to have the top face of the beams and the top face of the girders on the same elevation so that roof deck and floor decks can be placed on them. From the authors' teaching experience, the coping detail in particular, is difficult for students to comprehend from 2-D sketches.

One way to remedy this problem is to take students to actual construction sites. Although this is a good approach, it is a major challenge to find construction projects that are nearby and installing connections that coincides with the topic being taught at the time. Additionally, liability issues may also arise and prevent the faculty from taking students to construction sites. Because of thses issues, many faculty members have resorted to taking photoggraphs of connection types from construction sites and then showing them to their students. Unfortuantely, the photographs 
still do not show the true 3-dimensional nature of connections. In the summer of 1985, after seeing the inability of his students to visualisze even simple connections, Professor Duane Ellifritt of the University of Florida designed a steel connection sculpture as a visual aid to teach his students about the many ways steel members can be connected. The eight-feet, 2500-pounds duplicate of this sculpture has sprouted in over 150 campuses across the United States. In addition to the physical sculpture, the American Institute of Steel Construction (AISC) also has prepared a teaching guide for the connection types ${ }^{[26]}$, which can be downloaded from the AISC website.

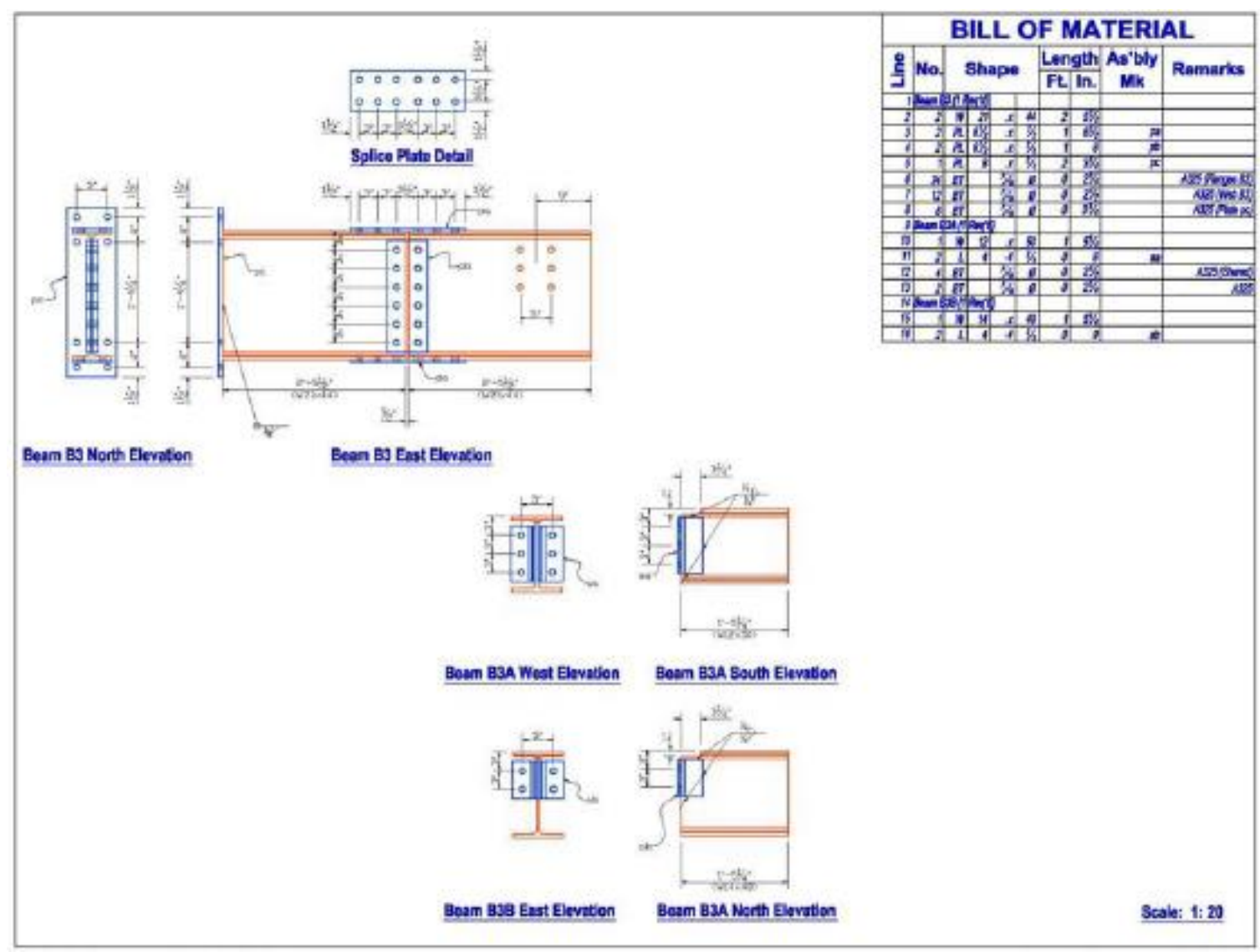

Figure 2 - Example of a typical shop drawing for connection shown in Figure $1^{[14]}$

\section{Steel sculpture - the virtual model}

Due to the large size of the physical steel sculpture, many schools have erected the sculpture outdoors. The cadets at the Military Academy at West Point fabricated a miniature sculpture on wheels. In many parts of the country, weather also makes it infeasible to use the steel sculpture as a teaching tool in the winter months or when it is dark out. This means that while the steel sculpture is a very powerful tool to visualize steel connections, the lack of continuous access makes it less effective as an instructional aid. To rectify this problem, development of a virtual sculpture began in 2006 as a class project at the authors' home institution. The first generation of the virtual sculpture was basically a set of interactive PowerPoint slides which include the close-up view of each connection, sample calculations and actual field applications of selected 
connections ${ }^{[28-30]}$. Feedback, related to the virtual sculpture as a learning aid, from students at Minnesota State University and Ghana (West Africa) was generally very positive. The main concern of the Ghanaian students was that the file size was too large.

The current interactive virtual sculpture was developed with a few goals in mind among which are:

- a platform that is commonly available to the users without additional cost;

- a stand-alone model so that no additional software is needed; and

- a completely self-guided model so that the student can use it as tutorial or reference.

The result is a virtual sculpture that was completely rebuilt from the beginning using the original blueprints provided by the fabricator of the physical sculpture housed on the campus of Minnesota State University. The platform chosen is Adobe's Portable Document Format (PDF). After the user downloads the sculpture to his/her computer, s/he will then have the full use of the learning aid.

Unlike the first generation of the virtual steel sculpture where the PowerPoint slides were produced using 2-D images. The current version was developed using Creo and Adobe animation that provide full $360^{\circ}$ view of the sculpture. Users can pan, rotate, zoom, and isolate any part of the sculpture. They can also select a connection to learn more about its design. In the following sections, we will describe the virtual sculpture in detail. Since the file for the fully animated virtual sculpture is too large to attach to this paper, readers are encouraged to visit: http://faculty.mnsu.edu/saeedmoaveni/.

Introductory Material

When the users access the above mentioned URL, they are greeted with the home page that has an image of the interactive steel sculpture. By clicking on the video button on the image, one can view a brief video that gives background on the development and overview of the virtual steel sculpture.

3D interactive sculpture

The 3D interactive sculpture (shown in Figure 3) is a solid model of the physical steel sculpture that is located at Minnesota State University, Mankato. The virtual steel sculpture is accessible $24 / 7$ and can be downloaded directly to users' computers.

\section{Close-Up Views}

As users manipulate the interactive sculpture, while holding down the Ctrl key they can click on any of the connections. Once a connection is clicked (for example, the connection circled in Figure 3), a new page is opened with the connection's close-up view (Figure 4). On the same page, the user can then choose to see the blueprints, field examples, sample calculations, or the finite element analysis (FEA) of that connection. A notable feature of these close-ups is that they provide multiple views of the connection of interest to allow the user to get a fuller picture of how, specifically, the components are connected. 


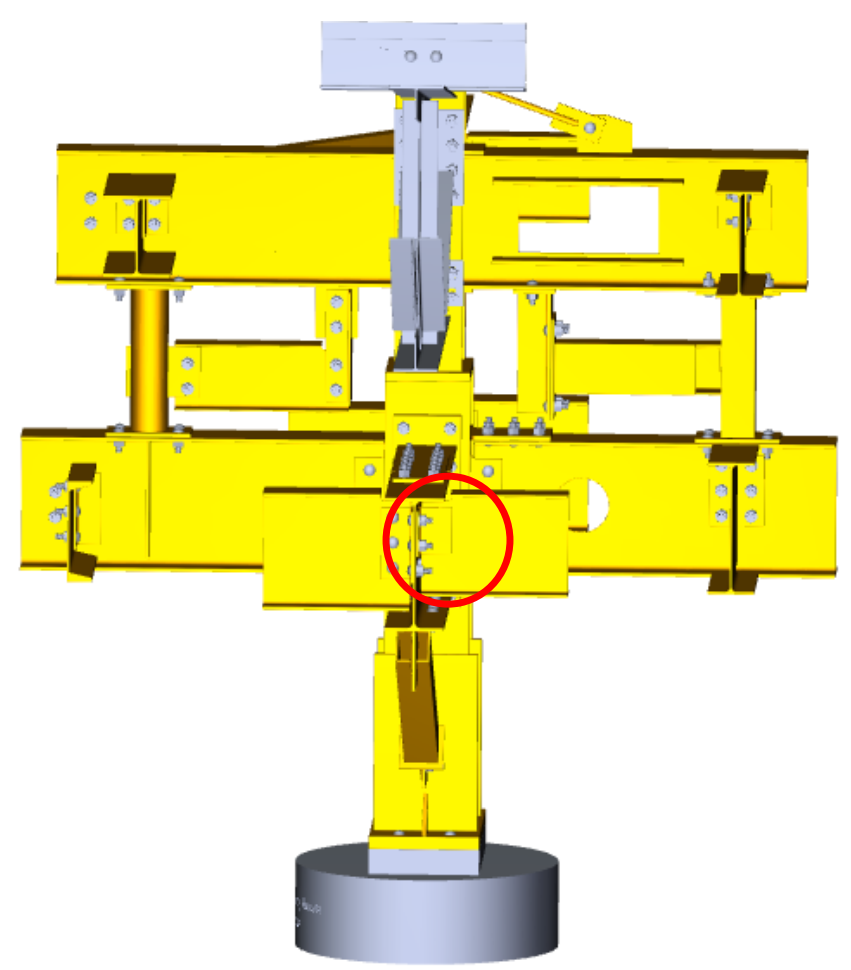

Figure 3 - The 3D Interactive Sculpture

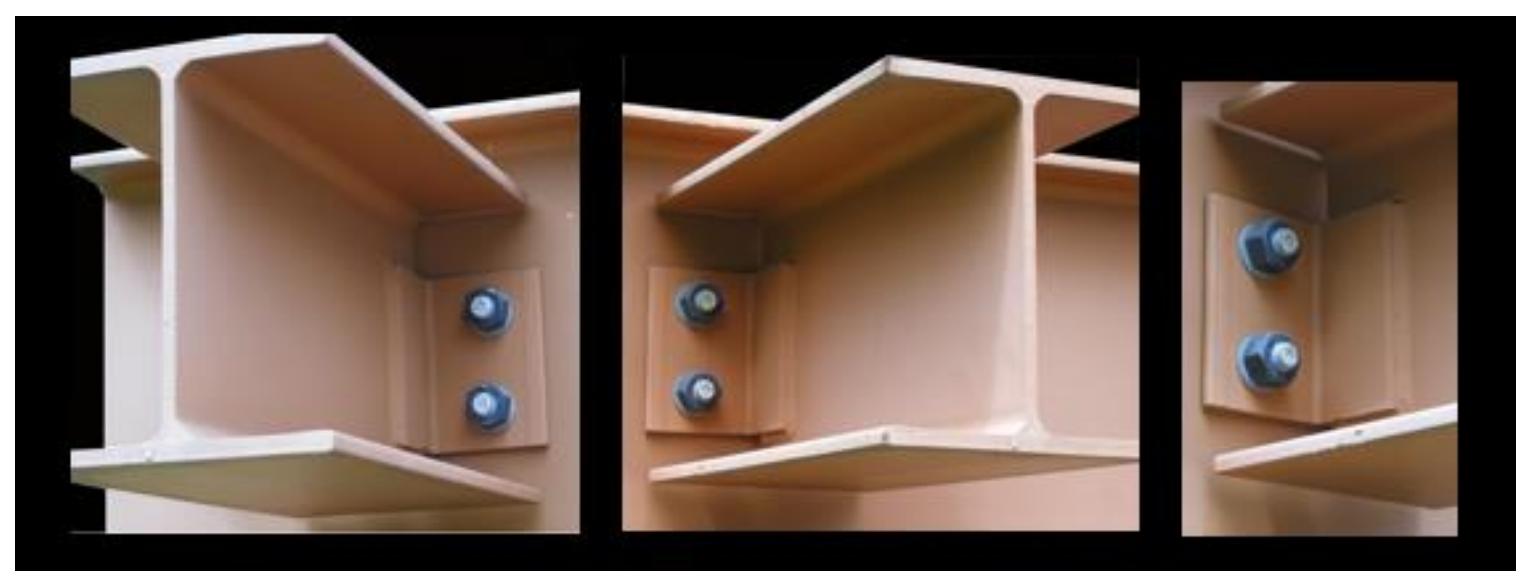

Figure 4 - Close-up views of steel connection circled in Figure 3

\section{Blueprints}

The blueprints that were created by the fabricator to make the physical steel sculpture are also available to view. Figure 5 shows the blueprint of the connection shown in Figure 4. These blueprints serve a dual purpose. The blue prints present the traditional orthographic views used by engineers and fabricators. When the photograph of a connection is presented with a corresponding blueprint, students would have more opportunities to learn the relationship between a 3 -dimensional object and its 2 -dimensional orthographic views. The second objective 
of showing the blueprints is to familiarize the students with construction document communication; how connection details are presented in industry. This is an important skill for students to develop. Students who are familiar with typical orthographic details will be better adapted to the information presented to them in professional practice. While 3-dimensional modeling of structures, such as work done in Revit, is becoming more common, it is still the industry standard to deliver 2-dimensional plans for purposes of construction. As such, it will be incumbent upon students to understand information presented in this way.

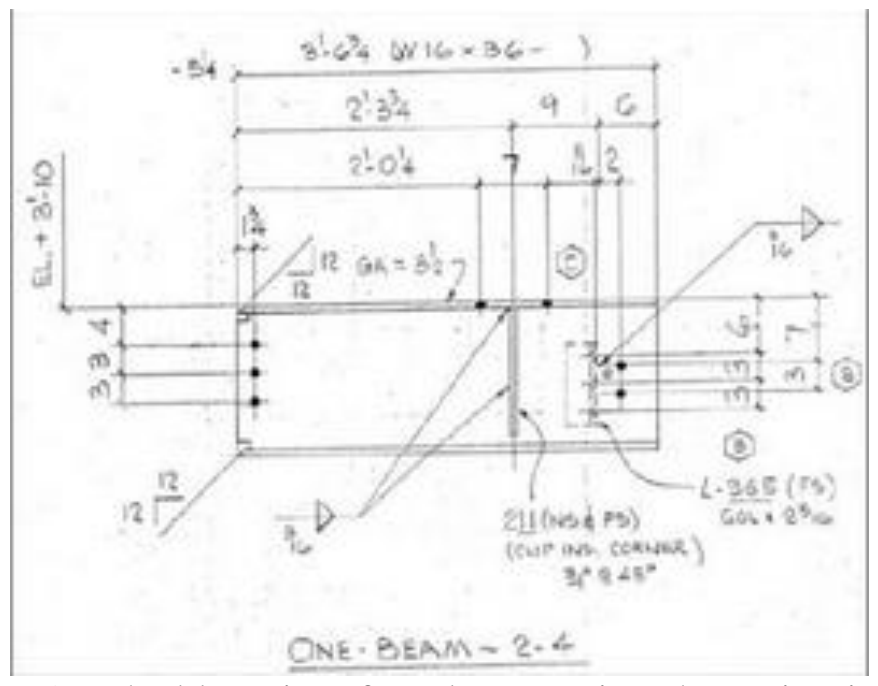

Figure 5 - The blueprint of steel connection shown in Figure 4

\section{Field Examples}

Prior to the development of a physical sculpture, and the virtual sculpture, the only way instructors could effectively show the assembly of steel connections was through examples in actual practice. As mentioned earlier, this created numerous liability and scheduling issues. To avoid this problem, instructors would often take photographs of connections on construction sites to present in the classroom. This approach is still effective and could complement the use of the virtual sculpture that is accessible to students $24 / 7$.

When a connection on the virtual sculpture is selected, an example from actual practice is an option that is available. This option would allow the students to see how a particular connection fits into a structural system. This will also provide contextual based relevance that reinforces the need to study the "glue" that holds structures together. 

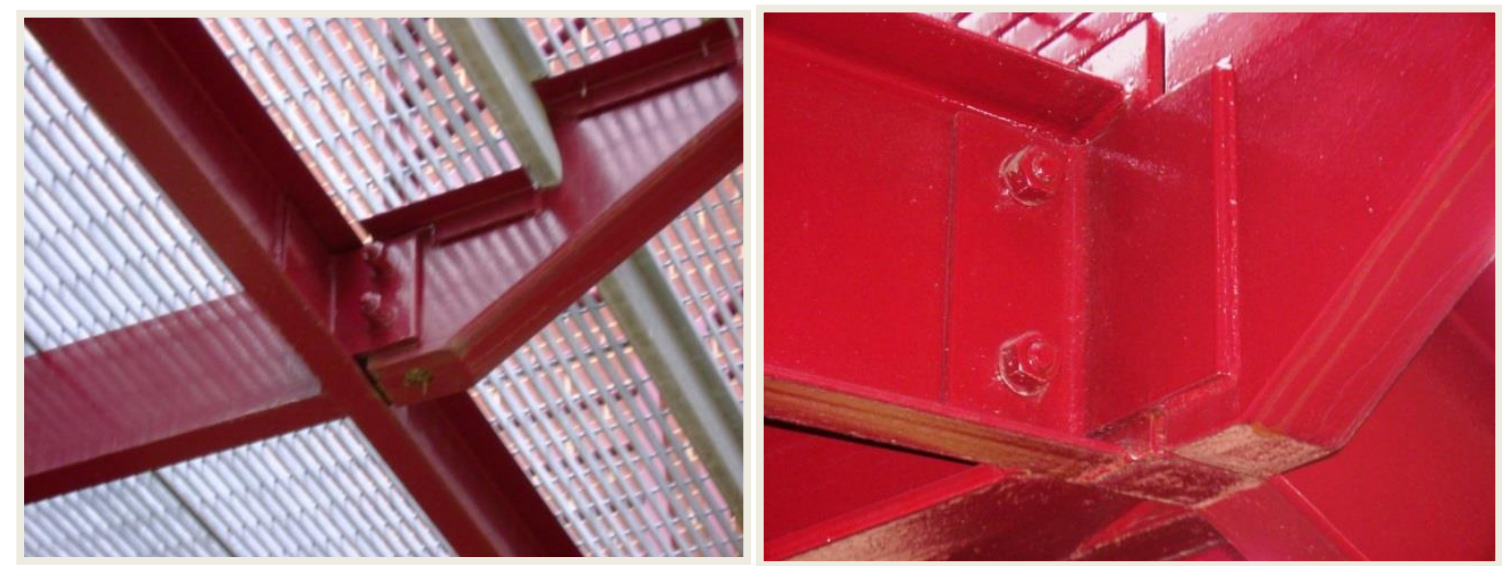

Figure 6 - The field example of connection shown in Figure 4

Sample Calculations

Design calculation is by far the most crucial portion of connection design. From the students' perspective, it may be the most important part as this is what they are being tested and graded for in class. This feature of the virtual sculpture provides a comprehensive set of calculations for a given connection. All the limit states as defined in the teaching guide for the connection types ${ }^{[26]}$ were considered in the sample calculation. As design is unique to each structure, the sample calculations illustrations of how one would calculate the capacity of each limit state and hence the limit of a given connection. The calculations were done in accordance to design specifications of the $14^{\text {th }}$ edition of the Steel Construction Manual ${ }^{\text {[27] }}$. Each set of calculations includes a problem statement, necessary free-body diagrams, and equations from the design specifications ${ }^{[27]}$ used. A complete set of sample calculations of the connection shown in Figure 4 is included in the Appendix.

\section{FEA Models}

The final feature of the virtual steel sculpture is the inclusion of the stress distribution in and within the vicinity of the connection. These FEA models allow students to visualize how stress is built up inside the connection as force is transferred from larger structural members to the connection. By providing this visualization, students will have a better understanding in identifying areas susceptible to failures.

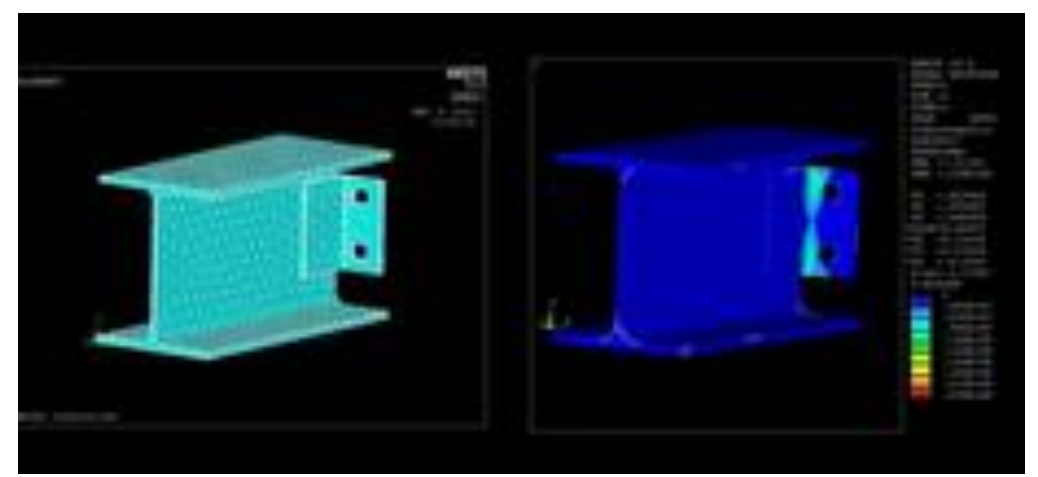

Figure 7 - FEA Model of connection shown in Figure 3 


\section{Conclusion}

Structural engineering is the oldest discipline in civil engineering. It is one of the most common areas used to fulfill ABET civil engineering program accreditation criteria. Typically, students would take a course in steel or reinforced concrete design or a combination of both after a structural analysis course to meet this proficiency requirement. A 8-ft, 2500-lb steel connection sculpture was designed and sponsored by AISC and its members to help students understand connection design. While this has many practical benefits, recognizing that the Google generation students are more computer savvy, an interactive (virtual) steel connection sculpture was developed as a learning tool to reach students in a way specialized to their generational qualities. Unlike the physical sculpture, this virtual sculpture is accessible 24/7. It includes a 3-D dynamic visualization, close-up views, field examples, sample calculations, and finite element analysis for each connection. This is all done in an effort to help students visualize the 3dimensional connection and understand its design and construction. Although connection design only comprises about $10 \%$ of a typical steel design course, connections are the glue that holds members of a structure together. Their design for loads and assembly would affect both safety and cost. Even when a connection is correctly designed for strength, if the assembly of the connection is complicated or practically infeasible, unnecessary errors may occur during fabrication and erection stages. This would either lead to an unsafe or extremely costly system.

Although the primary goal of the virtual steel sculpture is for a course specializing in steel design, this learning tool can help students taking other courses such as senior capstone design, statics, mechanics of materials, and structural analysis. Furthermore, this tool will benefit new engineers, architects, engineering technicians, and construction managers. With the potential of including sample calculations and field examples by colleagues from other countries, the tool also has the potential to benefit students and faculty globally.

\section{Acknowledgements}

The project was developed with the support from National Science Foundation under grant numbers: DUE-1140468 and DUE-1252371 and Program Officer Dr. Susan Finger. The authors are grateful for this support. The opinions and findings expressed in this paper are the sole responsibility of the authors. The student research assistants were: Lee Taylor, Thomas Gunderson, and James Sapp. JavaScript programming assistance was provided by Professor Guarionex Salivia of Computer Information Science Department at Minnesota State University.

\section{Bibliographies}

[1] Smith, E.A. and Epstein, H.I. (1980) "Hartford Coliseum Roof Collapse: Structural Collapse Sequence and Lessons Learned”, Civil Engineering, ASCE, April, pp.59-62.

[2] Pfrang, E.O. and Marshall, R. (1982) "Collapse of the Kansas City Hyatt Regency Walkways", Civil Engineering, ASCE, July, pp.65-68.

[3] Holt, R. and Hartmann, J. (2008) “Adequacy of the U10 \& L11 Gussett Plate Design of Minnesota Bridge No. 9340 (I-35W over Mississippi River”, Interim Report, Jan. 11.

[4] ASIC Code of Standard Practices for Steel Buildings and Bridges, AISC, March 2005. 
[5] Yan, S. "Understanding Generation Y"

http://www.oberlin.edu/stupub/ocreview/2006/12/08/features/Understanding_Generation_Y.html

[6] Junco, R. and Mastrodicasa, J. (2007) Connecting to the Net Generation: What Higher Education Professionals Need to Know About Today's Students, NASPA.

[7] Walter, E. (2012) Number Crunching: The Top 51 stats for Generation Y marketers, http://thenextweb.com/socialmedia/2012/01/21/number-crunching-the-top-51-stats-for-generation-ymarketers/\#!rnDxl.

[8] Lenhart, A., Ling, R., Campbell, S., Purcell, K. (2010) Teens and Mobile Phones, Washington, D.C.

[9] Meet the Class of 2015 (2011) Mr. Youth. New York, NY

[10] Brown, G. (2011) Mobile Youth Report 2011 mobileYouth.

[11] College Students: The Gadget Generation (2011), eMarketer, New York, NY.

[12] http://en.Wikipedia.org/wiki/Generation_Y, retrieved 12/21/08.

[13] Dennis, N. (2006) ASCE ExCEEd Teaching Workshop, http://www.asce.org/files/ppt/exceed/ARIntro.ppt. University of Arkansas, July $9-14$.

[14] ASCE ExCEEd workshop, http://www.asce.org/exceed/

[15] Bransford, J.D. (1979) Human Cognition: Learning, Understanding, and Remembering, Wadsworth, CA.

[16] Bransford, J.D., Stein, B.S., Vye, N.J., Franks, J.J., Auble, P.M., Mezynski, K.J., and Perfetto, G.A. (1983) "Differences in Approaches to Learning: An Overview," Journal of Experimental Psychology: General. Vol. 3, No. 4, pp. 390-398.

[17] Broudy, H.S. (1977) "Types of Knowledge and Purposes in Education," Schooling and the Acquisition of Knowledge, R.C. Anderson, R.J. Spiro, and W.E. Montague (Eds.), Erlbaum, NJ.

[18] Byrnes, J.P. (1996) Cognitive Development and Learning in Instructional Contexts, and Bacon, Boston.

[19] Chi, M.T.H., Bassok, M., Lewis, N.W., Reimann, P. , and Glaser, R. (1989) "Self-Explanations: How Students Study and Use Examples in Learning to Solve Problems," Cognitive Science, Vol. 13, pp. 145-182.

[20] Chi, M.T.H., deLeeuw, N., Chiu, M., and LaVancher, C. (1994) "Eliciting Self-Explanations Improves Understanding," Cognitive Science, Vol. 18, pp. 439-477.

[21] Luchins, A.S. and Luchins, E.H. (1970) Werbeimer's Seminar Revisited: Problem Solving and Thinking, Vol. 1, State University of New York Press, Albany, NY.

[22] Singley, K. and Anderson, J.R. (1989) The Transfer of Cognitive Skill, Harvard University Press, MA.

[23] Bransford, J.D., Brown, A.L., and Cocking, R.R. (eds.). (2000) How People Learn: Brain, Mind, Experience, and School, Expanded Edition, National Academy Press.

[24] Klausmeier, H.J. (1985) Education Psychology, 5th ed., Harper and Row, New York.

[25] Gick, M.L. and Holyoak, K.J. (1983) "Sch. Induction and Analogical Transfer," Cognitive Psychology, Vol. 15, pp. 1-38.

[26] Green, P.S., Sputo, T., and Veltri, P. "Connections Teaching Toolkit - A Teaching Guide for Structural Steel Connections", AISC.

http://www.aisc.org/Content/ContentGroups/Engineering_and_Research/Engineering_and_Research2/Teachi ng_Guide.pdf

[27] Manual of Steel Construction, (2011) 14th Edition, American Institute of Steel Construction (AISC), Chicago, IL.

[28] CHOU, K.C. and MOAVENI, S. (2009) "Web-Based Interactive Steel Sculpture for the Google Generation", Journal of STEM Education: Innovations \& Research, Vol. 10, Issue 3\& 4, pp 50-59.

[29] CHOU, K.C. and MOAVENI, S. (2009) "Making Steel Sculpture Available Online to Students in Developing Countries", International Journal of Modern Engineering, Volume 10, No.1, pp 45-54.

[30] AISC WET: Steel Educator's Tip Sheet, Nov-Dec 2008, http://cobweb.ecn.purdue.edu/ strsteel/TipSheet_Nov08.htm 
Appendix

Sample calculations of connection shown in Figure 4.

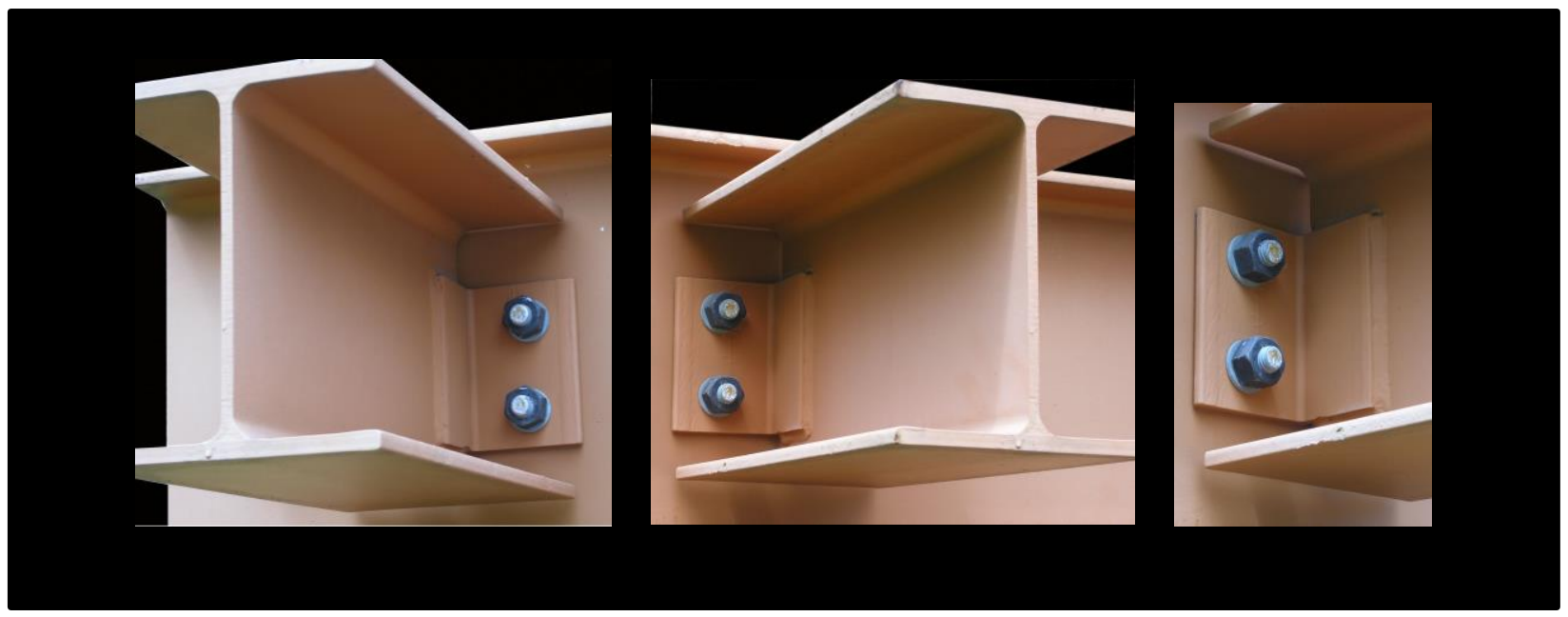

CONNECTION DESCRIPTION: Connection \#2 represents two W sections connected by two angles. This double angle connection is achieved by bolting one leg of the angle to the web of a beam (W section) and arc welding (fillet weld) the other leg of the angle to the web of a second beam (second $\mathrm{W}$ section) that is oriented out-of-plane-normal to the first beam. Note that an angle connector is placed on each side of the web of the second beam.

CONNECTION TyPE: Shear Connection

LIMIT STATES: Block Shear Rupture, Bolt Bearing Strength, Bolt Shear Strength, Flexural Yielding, Local Web Buckling, Shear Rupture, Shear Yielding, Weld Strength

ANALYSIS: Each limit state must be analyzed in accordance with the AISC Steel Construction Manual. The limit state with the lowest force capacity will control the connection.

\section{EXAMPLE:}

variables:

\begin{tabular}{|c|c|c|c|c|c|}
\hline$A_{b}:$ & cross-sectional area of bolt & $\left(\mathrm{in}^{2}\right)$ & $A_{g v}:$ & gross area in shear & $\left(\mathrm{in}^{2}\right)$ \\
\hline$A_{n t}:$ & net area in tension & $\left(\mathrm{in}^{2}\right)$ & $A_{n v}:$ & net area in shear & $\left(\mathrm{in}^{2}\right)$ \\
\hline $\mathrm{A}_{\mathrm{we}}$ : & effective area of the weld & $\left(\mathrm{in}^{2}\right)$ & $\mathrm{c}:$ & distance from neutral axis & (in) \\
\hline $\mathrm{d}_{\mathrm{b}}$ : & nominal bolt diameter & (in) & $\mathrm{d}_{\mathrm{h}}$ : & diameter of hole & (in) \\
\hline $\mathrm{F}_{\mathrm{EXX}}$ : & $\begin{array}{l}\text { filler metal classification } \\
\text { (electrode) strength }\end{array}$ & (ksi) & $F_{n v}:$ & nominal bolt shear strength & (ksi) \\
\hline $\mathrm{F}_{\mathrm{nw}}$ : & nominal shearing stress of weld & (ksi) & $\mathrm{F}_{\mathrm{u}}:$ & ultimate stress & (ksi) \\
\hline$F_{y}:$ & yield stress & (ksi) & $\mathrm{I}:$ & moment of inertia & $\left(\mathrm{in}^{4}\right)$ \\
\hline $\mathrm{L}:$ & length of weld & (in) & $\ell_{c}:$ & $\begin{array}{l}\text { clear distance in the direction } \\
\text { of the force }\end{array}$ & (in) \\
\hline
\end{tabular}


$\mathrm{n}:$ number of bolts

w: weld size t: thickness

(in.) $\mathrm{U}_{\mathrm{bs}}$ : tension stress variation factor

(in)

\section{Properties}

W Section: W 16x57 (Properties found in Table 1-1), W 12x58 (Properties found in Table 1-1), Angle: L 31/2 x 31/2 x 1/4 (Properties found in Table 1-7), All W Sections are A992 Steel $\left(\mathrm{F}_{\mathrm{y}}=50\right.$ $\mathrm{ksi}$ and $\mathrm{F}_{\mathrm{u}}=65 \mathrm{ksi}$, from Table 2-4), All other sections are A36 Steel $\left(\mathrm{F}_{\mathrm{y}}=36 \mathrm{ksi}\right.$ and $\mathrm{F}_{\mathrm{u}}=58$ $\mathrm{ksi}$, from Table 2-4), Bolts are 7/8" diameter A325N Steel $\left(\mathrm{F}_{\mathrm{nv}}=54 \mathrm{ksi}\right.$ and $\mathrm{F}_{\mathrm{nt}}=90 \mathrm{ksi}$, from Table J3-2), Welds use E70 Electrode $\left(\mathrm{F}_{\mathrm{EXX}}=70 \mathrm{ksi}\right)$
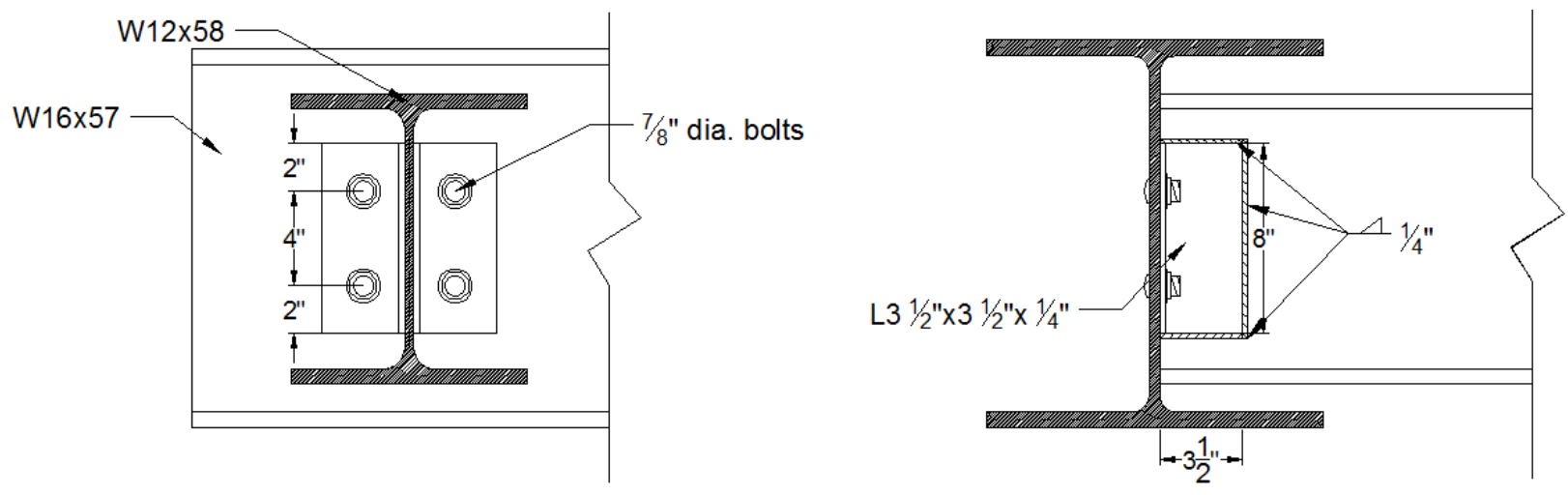

\section{Limit States}

A W $12 \times 58$ is connected, perpendicularly to a W $16 \times 57$ by two L $3 \frac{1}{2} \times 3 \frac{1}{2} \times 1 / 4$. Each angle is bolted by two bolts to the web of the W 16x57 beam and then welded to the web of the W $12 \times 58$ by arc welding with a $70 \mathrm{ksi}$ electrode. Find the maximum design shear force for the connection by analyzing all applicable limit states. Assume the force acts 1.5 " from the face of the W $12 \times 58$ beam.

\section{Block Shear Rupture (AISC J4.3)}

For Block Shear Rupture, the angle will control because it has the smallest tensile and shear yielding/rupture areas. Since both angles must rupture simultaneously, a multiplier of two is needed.

$$
R_{n}=\min \left\{\begin{array}{l}
0.60 F_{u} A_{n v}+U_{b s} F_{u} A_{n t} \\
0.60 F_{y} A_{g v}+U_{b s} F_{u} A_{n t}
\end{array}\right\}
$$

(Equation J4-5)

$\mathrm{F}_{\mathrm{y}}=36 \mathrm{ksi}$,

$\mathrm{F}_{\mathrm{u}}=58 \mathrm{ksi}$

Per angle:

$\mathrm{A}_{\mathrm{nv}}=[2+4-1-1(1 / 2)](1 / 4)=1.13 \mathrm{in}^{2}$

$\mathrm{U}_{\mathrm{bs}}=1.0$ (for uniform tension stress)

$\mathrm{A}_{\mathrm{nt}}=[1.75-1(1 / 2)](1 / 4)=0.32 \mathrm{in}^{2}$

$\mathrm{A}_{\mathrm{gv}}=6(1 / 4)=1.5 \mathrm{in}^{2}$

$R_{n}=\min \left\{\begin{array}{l}0.60(58)(1.13)+1.0(58)(0.32)=57.88 \mathrm{kips} \\ 0.60(36)(1.5)+1.0(58)(0.32)=50.96 \mathrm{kips}\end{array}\right\}$

$\mathrm{R}_{\mathrm{n}}=50.96$ kips controls

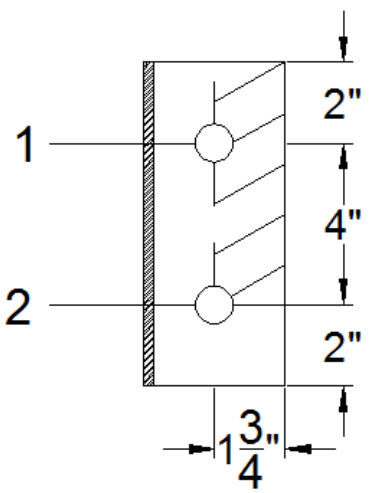


For 2 angles,

$\Phi \mathrm{R}_{\mathrm{n}}=.75(2)(50.96)=\mathbf{7 6 . 4 4}$ kips

Bolt Bearing Strength (AISC J3.10)

The angle is made from a weaker (lower rupture stress) material and has a smaller edge distance for the first bolt of the system, therefore holes in the angle will control. Furthermore, it was assumed that deformation at the bolt holes at service load is a design consideration. Since two angles are withstanding the force simultaneously, a multiplier of two is needed.

$$
R_{n}=\min \left\{\begin{array}{c}
1.2 \ell_{c} t F_{u} \\
2.4 d t F_{u}
\end{array}\right\}
$$

$\mathrm{R}_{\mathrm{n}}$ will be unique for bolt 1 and unique for bolt 2

Bolt 1

$\mathrm{d}=7 / 8$ in.

$\mathrm{d}_{\mathrm{h}}=\mathrm{d}+1 / 8=1$ in.

$\ell_{c}=\ell_{e}-h / 2=2.0-1 / 2=1.5 "$

$\mathrm{t}=0.25$ in.

$\mathrm{F}_{\mathrm{u}}=58 \mathrm{ksi}$

$R_{n}=\min \left\{\begin{array}{c}1.2 \ell_{c} t F_{u}=1.2(1.5)(.25)(58)=26.10 \mathrm{kips} / \mathrm{bolt} \\ 2.4 d t F_{u}=2.4(0.875)(.25)(58)=30.45 \mathrm{kips} / \mathrm{bolt}\end{array}\right\}$

Bolt 2

$\mathrm{d}=7 / 8$ in.

$\mathrm{d}_{\mathrm{h}}=\mathrm{d}+1 / 8=1$ in.

$\ell_{c}=s-h=4-1=3.0 \mathrm{in}$.

$\mathrm{t}=0.25$ in.

$\mathrm{F}_{\mathrm{u}}=58 \mathrm{ksi}$

$R_{n}=\min \left\{\begin{array}{c}1.2 \ell_{c} t F_{u}=1.2(3.0)(.25)(58)=52.2 \mathrm{kips} / \mathrm{bolt} \\ 2.4 d t F_{u}=2.4(0.875)(.25)(58)=30.45 \mathrm{kips} / \mathrm{bolt}\end{array}\right\}$

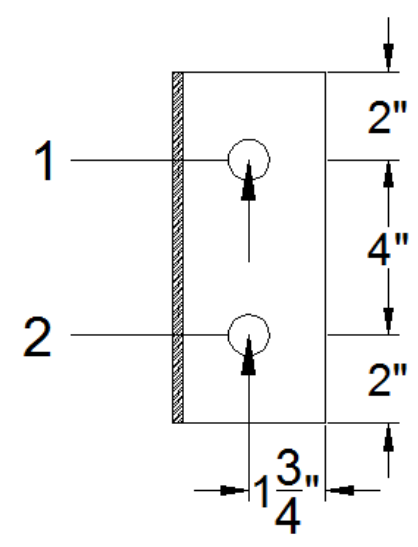

use $\mathrm{R}_{\mathrm{n}}=26.1$ kips for bolt 1 and 30.45 kips for bolt 2

$\Phi=.75$

$\Phi \mathrm{R}_{\mathrm{n}}=.75$ (2 angles) $[26.1+30.45]=\mathbf{8 4 . 8 3}$ kips

Bolt Shear Strength (AISC J3.6)

$\mathrm{F}_{\mathrm{nv}}=54 \mathrm{ksi}$

$$
R_{n}=n F_{n v} A_{b}
$$

(Equation J3-1)

$\mathrm{A}_{\mathrm{b}}=0.601 \mathrm{in}^{2}$

$\Phi \mathrm{R}_{\mathrm{n}}=.75(4$ bolts $)(54)(.601)=97.36$ kips 
Flexural Yielding (AISC J4.5)

From mechanics of materials,

$\mathrm{F}_{\mathrm{y}}=36 \mathrm{ksi}$

$$
R_{n}=\frac{F_{y} I}{e c}
$$

$\mathrm{I}=I_{\text {beam }}=475=475 \mathrm{in}^{4}$

$\mathrm{c}=\mathrm{h} / 2=6.1 \mathrm{in}$.

$\mathrm{e}=1.5 \mathrm{in}$.

$\Phi=0.90$

$\Phi R_{n}=0.90\left(\frac{50(475)}{1.5(6.1)}\right)=2336.07$ kips

Local Web Buckling (AISC Table B4.1b)

Compactness of the section must be checked to ensure that the member will be able to reach its' plastic limit before local failure occurs.

$\mathrm{E}=29,000 \mathrm{ksi}$

$$
\frac{h}{t_{w}} \leq 3.76 \sqrt{\frac{E}{F_{y}}}
$$

$\frac{h}{t_{w}}=27.0$ from AISC Table 1-1

$27.0 \leq 3.76 \sqrt{\frac{29,000}{50}}=90.55$ Therefore, the section is compact.

Shear Rupture of Angle (AISC J4.2)

The shear rupture for the angle controls because this limit state is based on the product of the materials ultimate stress and the sections net area in shear. The angle has both a lower stress and a smaller net area that the stress is distributed over than the w section, therefore it controls. Since there are two angles, a multiplier of two is needed.

$\mathrm{F}_{\mathrm{u}}=58 \mathrm{ksi}$

$$
R_{n}=0.60 F_{u} A_{n v}
$$

$\mathrm{A}_{\mathrm{nv}}=\left[\right.$ length $\left.-\mathrm{n}\left(\mathrm{d}_{\mathrm{h}}\right)\right] \mathrm{t}=[8-2(1)](1 / 4)=1.5 \mathrm{in}^{2}$

$\Phi=0.75$

$\Phi \mathrm{R}_{\mathrm{n}}=0.75(2$ angles $)(58)(1.5)=\mathbf{1 3 0 . 5} \mathbf{~ k i p s}$

\section{Shear Yielding of Angle (AISC J4.2)}

The shear yielding for the angle controls because this limit state is based on the product of the materials yield stress and the sections gross area in shear. The angle has both a lower stress and a smaller gross area that the stress is distributed over than the w section, therefore it controls. Since there are two angles, a multiplier of two is needed.

$\mathrm{F}_{\mathrm{y}}=36 \mathrm{ksi}$

$$
R_{n}=0.60 F_{y} A_{g v}
$$

$\mathrm{A}_{\mathrm{gv}}=8{ }^{\prime \prime}\left(1 / 4{ }^{\prime \prime}\right)=2.0 \mathrm{in}^{2}$ 
$\Phi=1.00$

$\Phi \mathrm{R}_{\mathrm{n}}=1(2)(36)(2)=144$ kips

Weld Strength (AISC J2.2)

For weld strength, we must check both the strength of the weld metal and the strength of the base metal.

Weld Metal Strength

$$
\begin{aligned}
& \qquad R_{n}=F_{n w} A_{w e} \\
& \mathrm{~F}_{\mathrm{nw}}=0.60 \mathrm{~F}_{\mathrm{EXX}}=0.60(70)=42 \mathrm{ksi} \quad(\text { Equation } \mathrm{J} 2-5) \\
& \mathrm{A}_{\mathrm{we}}=.707 \mathrm{wL}=.707(1 / 4)(8+3.5+3.5+8+3.5+3.5)=5.30 \mathrm{in}^{2} \\
& \Phi=0.75 \\
& \Phi \mathrm{R}_{\mathrm{n}}=.75[(42)(5.30)]=\mathbf{1 6 6 . 9 5} \mathrm{kips}
\end{aligned}
$$

Base Metal Strength - Check yield/rupture strength for base metal (W section) (AISC J4) Yield: $\Phi R_{n}=\Phi\left(0.60 F_{y} t L\right)$

$\Phi=1.00$

$\mathrm{F}_{\mathrm{y}}=50 \mathrm{ksi}$

$\mathrm{t}=0.360$ in.

$\mathrm{L}=3.5+3.5+8+3.5+3.5+8=30$ in.

$\Phi R_{n}=1(0.60)(50)(0.360)(30)=324 \mathrm{kips}$

Rupture: $\Phi R_{n}=\Phi\left(0.60 F_{u} t L\right)$

(Equation J2-3)

$\Phi=0.75$

$\mathrm{F}_{\mathrm{u}}=65 \mathrm{ksi}$

$\mathrm{t}=0.360$ in.

$\mathrm{L}=3.5+3.5+8+3.5+3.5+8=30$ in.

$\Phi R_{n}=.75(0.60)(65)(0.360)(15)=157.95 \mathrm{kips}$

\section{Example Summary}

Limit State

Block Shear Rupture

Bolt Bearing Strength

Bolt Shear Strength

Flexural Yielding

Local Web Buckling

Shear Rupture

Shear Yielding

Weld Strength

\author{
Max Factored Force \\ 76.44 kips \\ 84.83 kips \\ 97.36 kips \\ 2336.07 kips \\ Section is Compact \\ 130.5 kips \\ 144 kips \\ 166.95 kips
}


Therefore, Block Shear Rupture controls the design of the double angle connection with a maximum design shear force (including load factors) of 76.44 kips.
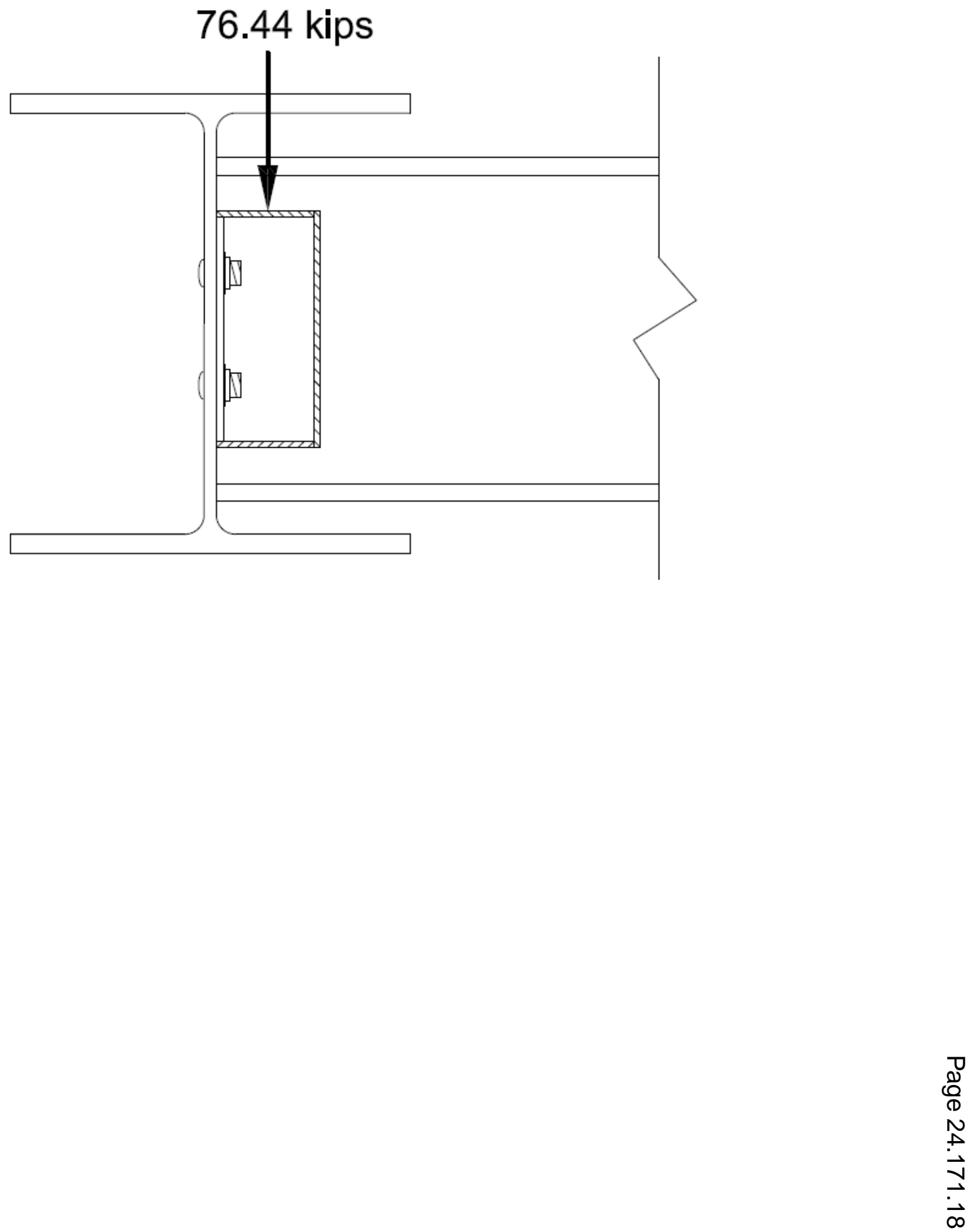